\title{
Cross-sectional study of Facebook addiction in a sample of
}

\section{Nepalese population [version 1; peer review: 2 approved with}

\section{reservations]}

\author{
Alok Atreya (D1, Samata Nepal (D1), Prakash Thapa² \\ ${ }^{1}$ Lumbini Medical College, Palpa, 32500, Nepal \\ ${ }^{2}$ Manipal College of Medical Sciences, Pokhara, Nepal
}

V1 First published: 14 Oct 2020, 9:1237

https://doi.org/10.12688/f1000research.26923.1

Latest published: $04 \mathrm{Dec}$ 2020, 9:1237

https://doi.org/10.12688/f1000research.26923.2

\section{Abstract}

Background: Facebook addiction is said to occur when an individual spends an excessive amount of time on Facebook, disrupting one's daily activities and social life. The present study aimed to find out the level of Facebook addiction in the Nepalese context and briefly discuss the issues associated with its unintended use.

Methods: A descriptive cross-sectional study was conducted in the Department of Forensic Medicine of Lumbini Medical College. The study instrument was the Bergen Facebook Addiction Scale typed into a Google Form and sent randomly to Facebook contacts of the authors. The responses were downloaded in a Microsoft Excel spreadsheet and analyzed using Statistical Package for Social Sciences version 16.

Results: The study consisted of 103 Nepalese participants, of which 54 $(52.42 \%)$ were males and 49 females (47.58\%). There were 11 participants $(10.68 \%)$ who had more than one Facebook account. When different approaches were applied it was observed that $8.73 \%$ $(n=9)$ to $39.80 \%(n=41)$ were addicted to Facebook.

Conclusion: When used properly Facebook has its own advantages. Excessive use is linked with health hazards including addiction and dependency. Students who engage more on Facebook may have less time studying, leading to poor academic performance. People need to be made aware of the issues associated with the misuse of Facebook.

\section{Keywords}

Addiction, Crime, Internet, Nepal, Social Networking

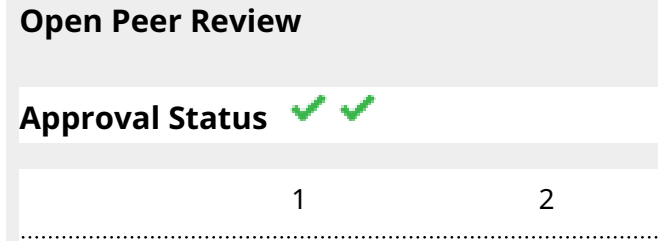

version 2

(revision)

04 Dec 2020

version 1

14 Oct 2020

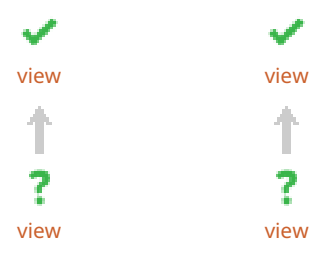

1. Kishor Adhikari (D), Chitwan Medical

College, Bharatpur, Nepal

Himalayan Environment and Public Health

Network (HEPHAN), Bharatpur, Nepal

2. Abhishek Das ID, Medical College, Kolkata, India

Any reports and responses or comments on the article can be found at the end of the article. 


\section{Corresponding author: Alok Atreya (alokraj67@hotmail.com)}

Author roles: Atreya A: Conceptualization, Data Curation, Formal Analysis, Methodology, Writing - Original Draft Preparation, Writing Review \& Editing; Nepal S: Data Curation, Formal Analysis, Methodology, Writing - Original Draft Preparation, Writing - Review \& Editing; Thapa P: Methodology, Supervision, Writing - Review \& Editing

Competing interests: No competing interests were disclosed.

Grant information: The author(s) declared that no grants were involved in supporting this work.

Copyright: ( $) 2020$ Atreya A et al. This is an open access article distributed under the terms of the Creative Commons Attribution License, which permits unrestricted use, distribution, and reproduction in any medium, provided the original work is properly cited.

How to cite this article: Atreya A, Nepal S and Thapa P. Cross-sectional study of Facebook addiction in a sample of Nepalese population [version 1; peer review: 2 approved with reservations] F1000Research 2020, 9:1237

https://doi.org/10.12688/f1000research.26923.1

First published: 14 Oct 2020, 9:1237 https://doi.org/10.12688/f1000research.26923.1 


\section{Introduction}

Founded on $4^{\text {th }}$ February 2004 for communication limited to Harvard students, Facebook today is the most used social networking service (SNS) worldwide. There are 1.59 billion active Facebook users daily and 2.41 billion active Facebook users monthly as of June $2019^{1}$. The primary motives of Facebook use are to communicate, collaborate and share content ${ }^{2}$. With such growing popularity and billions of users, there has been a concern of behavioral addiction to this SNS. Facebook addiction is said to occur when an individual spends an excessive amount of time on Facebook over the internet, disrupting one's daily activities and social life $\mathrm{e}^{3,4}$. If five hours or more is spent daily on Facebook then the person is said to be addicted to Facebook ${ }^{5}$.

The present study aimed to find out the level of Facebook addiction in a sample of Nepalese population and briefly discuss the issues associated with its unintended use.

\section{Methods}

A descriptive cross-sectional study was conducted in Department of Forensic Medicine of Lumbini Medical College after obtaining ethical approval from the Institutional Review Committee vide the letter IRC-LMC 01-G/019.

The Bergen Facebook Addiction Scale (BFAS) is a questionnaire that comprises of six core features of addiction: salience, mood modification, tolerance, withdrawal, conflict, and relapse ${ }^{6}$. Each of the six-core features consists of three questions, making a total of 18 questions. The final BFAS retained one question for each core element of addiction. Only the scores for questions $1,5,7,11,13$ and 16 determine the level of Facebook addiction. Each question is scored on a 5point Likert scale using anchors of 1: Very rarely and 5: Very often. Higher scores indicate greater Facebook addiction.

Participants scoring 4 (often) or 5 (very often) in four out of six questions were considered to be addicted to Facebook ${ }^{6,7}$. BASF has put forth two scoring schemes to determine Facebook addiction ${ }^{6}$. As per a polythetic scoring scheme, Facebook addiction was determined by a liberal approach, where a score of 3 or more was observed in at least four of six items; whereas using a conservative approach, a score of 3 or above in all six items determined Facebook addiction by a monothetic scoring scheme ${ }^{6}$.

Considering that there are around 1800 people in Lumbini Medical College including students, faculties and staffs, the sample size was calculated using the formula for finite population: $\mathrm{n}=\mathrm{N} * \mathrm{X} /(\mathrm{X}+(\mathrm{N}-1))$; taking a confidence level of $95 \%$ (Z-score $=1.96)$ and margin of error of $10 \%$, the sample size was calculated to be 92 .

The BAFS was typed into a Google Form and reviewed by all the authors for any mistakes which were then corrected. The link was then shared among the medical and nursing students, doctors, nurses and other health care staff working at Lumbini Medical College Teaching Hospital (LMCTH) through Facebook messenger, WhatsApp and Viber with a request to share the link among their friends or colleagues who were enrolled with LMCTH and were Nepalese citizens (convenient random sampling). The first part of the questionnaire consisted of a statement where it was explained that no financial or material gifts will be provided for completing the questionnaire. The survey did not collect any identifying information of any of the participants and the responses were anonymous. The second part of the questionnaire was a section on consent where the participants had an option to choose whether they voluntarily consented to participate or didn't consent. The third part of the questionnaire was accessible only to those participants who consented in the second part. The survey didn't continue for the participants who didn't consent and the incomplete form submitted. The link was made active on 27 July, 2019. On August 30, 2019 a total of 108 responses were received and the link was disabled from receiving further responses. There were five responses which were incomplete so those were excluded from the study. The obtained responses were downloaded as a Microsoft Excel spreadsheet, which was then exported into SPSS v16 for analysis. Descriptive statistics such as frequency, percentage, mean and standard deviation were used to determine demographic characteristics of the respondents and Facebook addiction (see Underlying data) ${ }^{8}$.

\section{Results}

The study sample consisted of 103 participants, of which 54 $(52.42 \%)$ were males and 49 females $(47.58 \%)$. There were 11 participants $(10.68 \%)$ who had more than one Facebook account (Table 1).

The majority of participants $(n=41,39.8 \%)$ responded that during the last year they often spent a lot of time thinking about Facebook or planned use of Facebook. When asked if they felt an urge to use Facebook more and more, 35 participants (34.0\%) felt they never felt such an urge. Only $16(15.5 \%)$ responders used Facebook to forget about their personal problems during the last year. The present study showed that $23.3 \%$ of the responders $(n=24 \%)$ could not cut down their use of Facebook during the last year. When asked whether they became restless or troubled when prohibited from using Facebook, six participants $(5.8 \%)$ responded that they often felt

\section{Table 1. Number of Facebook accounts of study participants.}

\begin{tabular}{|l|l|l|l|}
\hline $\begin{array}{l}\text { Facebook } \\
\text { accounts }\end{array}$ & Male N (\%) & $\begin{array}{l}\text { Female } \\
\text { N (\%) }\end{array}$ & Total N (\%) \\
\hline One & $46(44.66)$ & $46(44.66)$ & $92(89.32)$ \\
\hline $\begin{array}{l}\text { More than } \\
\text { one }\end{array}$ & $8(7.76)$ & $3(2.92)$ & $11(10.68)$ \\
\hline Total & $54(52.42)$ & $49(47.58)$ & $103(100)$ \\
\hline
\end{tabular}


restless. In 21 participants (20.4\%), their use of Facebook had a negative impact on their job/studies. The detailed responses of the participants are presented in Table 2 and Table 3.

There were ten participants $(9.70 \%)$ who scored 4 or more in four questions. A 43-year-old male was among one of those seven participants who had multiple Facebook accounts and scored 5 in all the six questions. This was the maximum score one could get as per BFAS, which denotes this individual was severely addicted to Facebook use. As per the conservative approach there were only nine participants (8.73\%) who were addicted to Facebook. When the liberal approach was used, there were 41 participants $(39.80 \%)$ who were addicted to Facebook (Table 4).

\section{Discussion}

Although the popularity of Facebook is increasing daily, the fact that its use is prone to addiction cannot be denied'. Many recent studies from around the world advocate the potential risk of addiction. There are various assessment tools and diagnostic criteria to investigate SNS addiction; however, BFAS is considered to have good psychometric properties ${ }^{10}$. Facebook can be used for various purposes like instant messaging, video conferencing, gaming and shopping. Facebook is popular for its content sharing feature. The shared content may be news, personal blogs, pictures and videos, which can be educational, entertaining or explicit.

In a study conducted among postgraduate medical students in Southern India, it was observed that $26 \%$ of the participants were addicted to Facebook and $33 \%$ had the possibility of addiction ${ }^{11}$. The study also concluded that loneliness influenced Facebook addiction.

A Nepalese study on Facebook use conducted among health science students of a private medical college showed that $98.2 \%$ were active Facebook users ${ }^{12}$. The authors of the study concluded that $28.5 \%$ of the study participants were unable to reduce their time spent on Facebook and therefore were addicted. In contrast, the present study observed as little as $8.73 \%$ of participants addicted to Facebook use. Although the number may seem less, it still raises a concern over the use of SNS in Nepalese context. Excessive use of Facebook by students may lead to poor time management and less time studying, which would result in poor academic performance. Another reason for fewer participants with Facebook addiction in the present study might be the fact that the majority of the participants were health care professionals.

Table 2. Items in the questionnaire and responses of the participants $(n=103)$.

\begin{tabular}{|c|c|c|c|c|c|}
\hline \multirow[t]{2}{*}{ Items in the questionnaire } & \multicolumn{5}{|c|}{ Responses in 5-point scale $\mathbf{N}(\%)$} \\
\hline & 1 & 2 & 3 & 4 & 5 \\
\hline $\begin{array}{l}\text { How often during the last year } \\
\text { have you spent a lot of time } \\
\text { thinking about Facebook or } \\
\text { planned use of Facebook? }\end{array}$ & $10(9.7)$ & $10(9.7)$ & $42(40.8)$ & $28(27.2)$ & $13(12.6)$ \\
\hline $\begin{array}{l}\text { How often in the last year } \\
\text { have you felt an urge to use } \\
\text { Facebook more and more? }\end{array}$ & $11(10.7)$ & $24(23.3)$ & 39 (37.9) & $22(21.4)$ & $7(6.8)$ \\
\hline $\begin{array}{l}\text { How often during the last } \\
\text { year have you used Facebook } \\
\text { in order to forget about } \\
\text { personal problems? }\end{array}$ & $30(29.1)$ & $31(30.1)$ & $26(25.2)$ & $9(8.7)$ & $7(6.8)$ \\
\hline $\begin{array}{l}\text { How often during the last year } \\
\text { have you tried to cut down on } \\
\text { the use of Facebook without } \\
\text { success? }\end{array}$ & $22(21.4)$ & $30(29.1)$ & $27(26.2)$ & $16(15.5)$ & $8(7.8)$ \\
\hline $\begin{array}{l}\text { How often during the last year } \\
\text { have you become restless } \\
\text { or troubled if you have } \\
\text { been prohibited from using } \\
\text { Facebook? }\end{array}$ & $42(40.8)$ & $37(35.9)$ & $18(17.5)$ & $3(2.9)$ & $3(2.9)$ \\
\hline $\begin{array}{l}\text { How often during the last } \\
\text { year have you used Facebook } \\
\text { so much that it has had a } \\
\text { negative impact on your } \\
\text { job/studies? }\end{array}$ & $26(25.2)$ & $29(28.2)$ & $27(26.2)$ & $20(19.4)$ & $1(1.0)$ \\
\hline
\end{tabular}


Table 3. Items in the questionnaire and responses where the score is 4 or more $(n=103)$.

\begin{tabular}{|l|l|}
\hline Items in the questionnaire & $\begin{array}{l}\text { Responses } \\
\text { N (\%) }\end{array}$ \\
\hline $\begin{array}{l}\text { How often during the last year have you spent a } \\
\text { lot of time thinking about Facebook or planned } \\
\text { use of Facebook? }\end{array}$ & 41 (39.8) \\
\hline $\begin{array}{l}\text { How often in the last year have you felt an urge to } \\
\text { use Facebook more and more? }\end{array}$ & 29 (28.2) \\
$\begin{array}{l}\text { How often during the last year have you used } \\
\text { Facebook in order to forget about personal } \\
\text { problems? }\end{array}$ & 16 (15.5) \\
$\begin{array}{l}\text { How often during the last year have you tried to } \\
\text { cut down on the use of Facebook without success? }\end{array}$ & 24 (23.3) \\
\hline $\begin{array}{l}\text { How often during the last year have you become } \\
\text { restless or troubled if you have been prohibited } \\
\text { from using Facebook? }\end{array}$ & 6 (5.8) \\
\hline $\begin{array}{l}\text { How often during the last year have you used } \\
\text { Facebook so much that it has had a negative } \\
\text { impact on your job/studies? }\end{array}$ & 21 (20.4) \\
\hline
\end{tabular}

Table 4. Facebook addiction of the study participants $(n=103)$.

\begin{tabular}{|l|l|l|l|}
\hline \multirow{2}{*}{ Facebook addiction } & \multicolumn{2}{|l|}{ Gender N (\%) } & Total N (\%) \\
\cline { 2 - 4 } & Male & Female & \\
\hline Scored $\geq 4$ in $\geq 4$ items & $4(3.88)$ & $6(5.82)$ & $10(9.70)$ \\
\hline $\begin{array}{l}\text { Scored } \geq 3 \text { in all } 6 \text { items } \\
\text { (Conservative approach) }\end{array}$ & $6(5.82)$ & $3(2.91)$ & $9(8.73)$ \\
\hline $\begin{array}{l}\text { Scored } \geq 3 \text { in } \geq 4 \text { items } \\
\text { (Liberal approach) }\end{array}$ & $22(21.36)$ & $19(18.44)$ & $41(39.80)$ \\
\hline
\end{tabular}

There is restricted access to Facebook and other SNS sites in many hospitals. Medical schools including Lumbini Medical College, Palpa; Manipal Teaching Hospital, Pokhara and Nepal Medical College, Kathmandu have blocked access to Facebook from their internet servers.

A study conducted among 355 university students in the Philippines observed that only 15 were Facebook addicts? A study from the United States showed that nearly $96 \%$ of medical undergraduates regularly used Facebook for social life and academic pursuits ${ }^{13}$. One of the studies conducted in Nepal stated Facebook to be a novel way of communication with members of health professional associations ${ }^{14}$.

One of the underlying reasons for excessive use of Facebook may be narcissistic behavior in which the individual is frequently sharing content to gain interactions and positive feedback in an attempt to become popular and admired ${ }^{15}$. The feeling of happiness tempts the individual to maintain and increase the level of happiness by engaging more on Facebook. Frequent use of Facebook can also lead to a person revealing his/her personal information like place of residence, job, family members etc. People should be made aware of the fact that this information can be used by individuals who take undue advantages or have ulterior motives. The increasing popularity of Facebook and other SNS sites is an indicator of people being more engaged in the online world. It has been observed that loneliness is one of the dominant predictors of social media addiction including Facebook $^{16}$. We are not far from receiving patients with a complaint of excessive use of SNS sites or the internet in Nepalese hospitals. The clinicians should be aware that treatment in case of Facebook addiction can never be complete abstinence as the internet has become an integral part of social culture. Treatment in such cases should be aimed at controlled use and identifying the underlying cause of compulsive overuse.

The present study is not without limitations. The study participants were chosen through searching the researcher's Facebook friend list, and there is a possible sampling bias in our study. The responses were collected anonymously and no identifying information of the responder was recorded; it therefore cannot be known if multiple responses form a same person occurred. Three different approaches were used in the present study that showed a varied addiction rate in the same population. BFAS is based upon use of Facebook, but it doesn't specify the type of addiction is to technology or content. The convenient sampling, age, gender and occupational imbalance of the present study therefore cannot be generalized to the population of Nepal as a whole.

\section{Conclusions}

Facebook addiction in the Nepalese context as per the present study was at least $8.73 \%$, with a possibility a prevalence of addiction up to $39.80 \%$. When used properly, SNS and the internet have their own advantages. Excessive use is linked with health hazards including addiction and dependency. People need to be made aware of misuse of SNS and the associated issues. Complete abstinence from Facebook or any SNS is difficult to achieve as internet has become integral part of our lives; however, in case of excessive use patients can be advised to control their use. Considering the high popularity of Facebook and other SNS sites in Nepal, it is evident that there is a huge need for future research in this regard.

\section{Data availability}

Underlying data

DRYAD: Cross-sectional study of Facebook addiction in a sample of Nepalese population. https://doi.org/10.5061/ dryad.83bk3j9pv ${ }^{8}$.

Data are available under the terms of the Creative Commons Zero "No rights reserved" data waiver (CC0 1.0 Public domain dedication). 
1. Facebook Newsroom [Internet]. [cited 2019 Nov 18] Reference Source

2. Thurairaj S, Hoon EP, Roy SS, et al.: Reflections of students' language usage in social networking sites: Making or marring academic English. The Electronic Journal of e-Learning. 2015; 13(4): 302-16. Reference Source

3. Rana MS, Ahmed O, Hossain MA: Facebook addiction, self-esteem, and life satisfaction of Bangladeshi young people. Dhaka Univ J Psych. 2016; 40: 29-41. Reference Source

4. Mekinc J, Smailbegovic T, Kokic A: Should we be concerned about children using the internet: pilot study. Innov Issues Approaches Soc Sci. 2013; 6(2): $6-20$. Publisher Full Text

5. Karaiskos D, Tzavellas E, Balta G, et al.: P02-232 - Social network addiction: a new clinical disorder? Eur Psychiatry. 2010; 25(Supplement 1): 855. Publisher Full Text

6. Andreassen CS, Torsheim T, Brunborg GS, et al.: Development of a Facebook Addiction Scale. Psychol Rep. 2012; 110(2): 501-17. PubMed Abstract | Publisher Full Text

7. Marcial DE: Are you a Facebook addict? Measuring Facebook addiction in the Philippine University. Int Proc Econ Dev Res. 2013; 66: 12-15. Reference Source

8. Atreya A, Nepal S, Thapa P: Cross-sectional study of Facebook addiction in sample of Nepalese population, v3, Dryad. Dataset 2020 http://www.doi.org/10.5061/dryad.83bk3j9pv

9. Griffiths MD: Facebook addiction: concerns, criticism, and recommendations--a response to Andreassen and colleagues. Psychol Rep. 2012; 110(2): 518-20.

PubMed Abstract | Publisher Full Text

10. Kuss DJ, Griffiths MD: Social Networking Sites and Addiction: Ten Lessons Learned. Int J Environ Res Public Health. 2017; 14(3): 311. PubMed Abstract | Publisher Full Text | Free Full Text

11. Shettar M, Karkal R, Kakunje A, et al.: Facebook addiction and loneliness in the post-graduate students of a university in southern India. Int / Soc Psychiatry. 2017; 63(4): 325-329. PubMed Abstract | Publisher Full Text

12. Jha RK, Shah DK, Basnet S, et al.: Facebook use and its effects on the life of health science students in a private medical college of Nepal. BMC Res Notes. 2016; 9: 378.

PubMed Abstract | Publisher Full Text | Free Full Text

13. Gafni R, Deri M: Costs and benefits of facebook for undergraduate students. Interdisciplinary Journal of Information, Knowledge, and Management 2012; 7: 45-61. Reference Source

14. Chaudhary $\mathrm{P}$, Tuladhar $\mathrm{H}$ : Novel ways of improving communication with members of health professional associations. Int J Gynaecol Obstet. 2014; 127 Suppl 1: S15-6. PubMed Abstract | Publisher Full Text

15. Brailovskaia J, Schillack $H$, Margraf J: Facebook Addiction Disorder in Germany. Cyberpsychol Behav Soc Netw. 2018; 21(7): 450-456. PubMed Abstract | Publisher Full Text

16. Biolcati R, Mancini G, Pupi V, et al.: Facebook Addiction: Onset Predictors. I Clin Med. 2018; 7(6): 118

PubMed Abstract | Publisher Full Text | Free Full Text 


\section{Open Peer Review}

\section{Current Peer Review Status: ? ?}

\section{Version 1}

Reviewer Report 20 November 2020

https://doi.org/10.5256/f1000research.29737.r74539

(C) 2020 Das A. This is an open access peer review report distributed under the terms of the Creative Commons Attribution License, which permits unrestricted use, distribution, and reproduction in any medium, provided the original work is properly cited.

Abhishek Das

Department of Forensic and State Medicine, Medical College, Kolkata, West Bengal, India

The cross sectional study done is presented well with originality.

The Abstract reflects the major aspects of the main paper. However, the different approaches mentioned here needs a little elaboration. Inclusion of the keyword "Facebook" would be beneficial.

The Introduction properly reflects the background of study, but needs to highlight more on existing gap in literature. The level of addiction should be clarified clearly.

The Methods section is well written and can be replicated later by others. However the convenience sampling could have been improved by choosing the portion of general Nepali population attending hospital apart from only including those attached to LMCTH. Exactly how many participants approached (google form sent) was not mentioned clearly, so the response rate to BFAS in this study could not be calculated. The response to the SIX core features of the addiction was not mentioned in detail in Results section.

Two wrong representations of data noted:

1. 'BAFS' is to be replaced by BFAS in the first line of last paragraph of methods section.

2. In the description of Tables $2 \& 3$ on "who could not cut down their use of Facebook during the last year" the result should be $n=24$ without the $\%$ sign.

Overall, this is a well formulated and executed study with authentic results.

Is the work clearly and accurately presented and does it cite the current literature? Yes

Is the study design appropriate and is the work technically sound? Partly 
Are sufficient details of methods and analysis provided to allow replication by others? Yes

If applicable, is the statistical analysis and its interpretation appropriate? Partly

Are all the source data underlying the results available to ensure full reproducibility? Yes

Are the conclusions drawn adequately supported by the results? Yes

Competing Interests: No competing interests were disclosed.

Reviewer Expertise: Forensic medicine, forensic psychiatry, medical education are my field of research.

I confirm that I have read this submission and believe that I have an appropriate level of expertise to confirm that it is of an acceptable scientific standard, however I have significant reservations, as outlined above.

Author Response 25 Nov 2020

Alok Atreya, Lumbini Medical College, Palpa, Nepal

We would like to thank the learned reviewer for the detailed review and positive comments on our manuscript. Based upon the comments the following changes are made:

Comment 1: The cross-sectional study done is presented well with originality.

Response: Thank you for the comment.

Comment 2: The Abstract reflects the major aspects of the main paper. However, the different approaches mentioned here needs a little elaboration.

Response: The different approaches that were used for e.g. polythetic and monothetic scoring scheme are detailed in the methods and results section so it was removed from here to avoid confusion. The sentence "When different approaches were applied it was observed that $8.73 \%(n=9)$ to $39.80 \%(n=41)$ were addicted to Facebook." is reframed to "It was observed that $8.73 \%(n=9)$ to $39.80 \%(n=41)$ were addicted to Facebook."

Comment 3: Inclusion of the keyword "Facebook" would be beneficial.

Response: Facebook is added as a keyword.

Comment 4: The Introduction properly reflects the background of study, but needs to highlight more on existing gap in literature. The level of addiction should be clarified clearly.

Response: The last paragraph is elaborated as:

"Excessive use of Facebook and other SNS is linked with health hazards including addiction and dependency. However, limited number of studies in this regard has made it a rarity in 
Nepalese context. The present study is therefore aimed to find out the level of Facebook addiction in a sample of Nepalese population and briefly discuss the issues associated with its unintended use."

Comment 5: The Methods section is well written and can be replicated later by others. However the convenience sampling could have been improved by choosing the portion of general Nepali population attending hospital apart from only including those attached to LMCTH.

Response: We are grateful for the suggestion and will keep it in mind for future works. The study population for the present study are students (medical and nursing) and employees of Lumbini Medical College, Palpa. Although, the Nepalese students studying in the college are from different parts of the country and so are the employees; we have used the term 'sample of Nepalese population'.

Comment 6: Exactly how many participants approached (google form sent) was not mentioned clearly, so the response rate to BFAS in this study could not be calculated.

Response: This was one of the limitations of the study. We have added the following sentence as limitation: "As the study participants were requested to share the link among the students and employees of LMCTH, we could not calculate the number people approached and the response rate."

Comment 7: The response to the SIX core features of the addiction was not mentioned in detail in Results section.

Response: Table 2 and Table 3 detail the responses on the six core features of addiction.

Comment 8: Two wrong representations of data noted:

'BAFS' is to be replaced by BFAS in the first line of last paragraph of methods section. In the description of Tables 2 \& 3 on "who could not cut down their use of Facebook during the last year" the result should be $n=24$ without the $\%$ sign.

Response: Corrected.

Comment 9: Overall, this is a well formulated and executed study with authentic results. Response: Thank you.

Competing Interests: No competing interests were disclosed.

Reviewer Report 03 November 2020

https://doi.org/10.5256/f1000research.29737.r73468

(c) 2020 Adhikari K. This is an open access peer review report distributed under the terms of the Creative Commons Attribution License, which permits unrestricted use, distribution, and reproduction in any medium, provided the original work is properly cited.

\section{Kishor Adhikari}


Department of Community Medicine and Public Health, Chitwan Medical College, Bharatpur, Nepal

2 Himalayan Environment and Public Health Network (HEPHAN), Bharatpur, Nepal

Title: The authors have taken samples from only one medical college of Nepal, so, it may not look correct to state as "Nepalese population".

Method: There is no sampling technique as "Convenient random sampling". It is better to keep as convenient sampling.

Conclusion: Don't keep many things which are not the findings of your research.

\section{References}

1. Jha RK, Shah DK, Basnet S, Paudel KR, et al.: Facebook use and its effects on the life of health science students in a private medical college of Nepal.BMC Res Notes. 2016; 9: 378 PubMed Abstract | Publisher Full Text

Is the work clearly and accurately presented and does it cite the current literature? Yes

Is the study design appropriate and is the work technically sound?

Yes

Are sufficient details of methods and analysis provided to allow replication by others? Partly

If applicable, is the statistical analysis and its interpretation appropriate? Partly

Are all the source data underlying the results available to ensure full reproducibility? Yes

Are the conclusions drawn adequately supported by the results? Partly

Competing Interests: No competing interests were disclosed.

Reviewer Expertise: Non communicable disease risk factors, health system

I confirm that I have read this submission and believe that I have an appropriate level of expertise to confirm that it is of an acceptable scientific standard, however I have significant reservations, as outlined above. 
Alok Atreya, Lumbini Medical College, Palpa, Nepal

We would like to thank the learned reviewer for the detailed review and positive comments on our manuscript. Based upon the comments the following changes are made:

Comment 1 Title: The authors have taken samples from only one medical college of Nepal, so, it may not look correct to state as "Nepalese population".

Response: The study population for the present study are students (medical and nursing) and employees of Lumbini Medical College, Palpa. The Nepalese students studying in the college are from different parts of the country and so are the employees. However, the whole Nepalese population cannot be represented by this study we have used the term 'sample of Nepalese population' in the title.

Comment 2 Method: There is no sampling technique as "Convenient random sampling". It is better to keep as convenient sampling.

Response: Changed as instructed.

Comment 3 Conclusion: Don't keep many things which are not the findings of your research. Response: Conclusion is shortened and only the relevant findings are included.

Competing Interests: No competing interests were disclosed.

\section{Comments on this article}

\section{Version 1}

\section{Reviewer Response 03 Dec 2020}

Kishor Adhikari, Chitwan Medical College, Bharatpur, Nepal

I had mistakenly suggested the reference (Jha et al.) in my review as it was one of the studies with similar nature to my comment without noticing the same reference in the list. Apologies for the inconvenience that occurred.

Competing Interests: NO competing interest. 
The benefits of publishing with F1000Research:

- Your article is published within days, with no editorial bias

- You can publish traditional articles, null/negative results, case reports, data notes and more

- The peer review process is transparent and collaborative

- Your article is indexed in PubMed after passing peer review

- Dedicated customer support at every stage

For pre-submission enquiries, contact research@f1000.com 